\title{
Effect of Temperature and Water Activity on the Growth of Cladosporium sphaerospermum and Cladosporium cladosporioides
}

\author{
MAKI AIHARA $^{1 *}$, TATSUAKI TANAKA ${ }^{2}$, TOSHIKO OHTA $^{3}$ \\ AND KOSUKE TAKATORI ${ }^{1}$ \\ 'National Institute of Health Sciences, 1-18-1, Kamiyoga, Setagaya-ku, Tokyo 158-8501, \\ ${ }^{2}$ Ochanomizu University, 2-1-1, Otsuka, Bunkyo-ku, Tokyo 112-8610 and \\ ${ }^{3}$ Sagami Women's University, 2-1-1, Bunkyo, Sagamihara-city, Kanagawa 228-8533, Japan
}

Received 4 October 2000/Accepted 25 February 2002

\begin{abstract}
The effects of temperature and water activity (Aw) were studied on the growth activity of Cladosporium sphaerospermum and $C$. cladosporioides. High growth was noted in $C$. sphaerospermum at high temperatures and in $C$. cladosporioides at low temperatures, but the growth activity of both $C$. sphaerospermum and $C$. cladosporioides was similar at $23-30^{\circ} \mathrm{C}$. With regard to $\mathrm{Aw}$, growth of $\boldsymbol{C}$. cladosporioides was greater than that of $C$. sphaerospermum at $10-23^{\circ} \mathrm{C}$. At $32-36^{\circ} \mathrm{C}$, higher activities were shown in $C$. sphaerospermum. $C$. sphaerospermum and $C$. cladosporioides showed morphological changes such as dark brown hyphae with thick and cigar shaped cells, and irregulary swollen cells at low Aw. C. sphaerospermum showed a broader range of growth temperature and Aw than $C$. cladosporioides.
\end{abstract}

Key words : Cladosporium sphaerospermum/Cladosporium cladosporioides/ Temperature/Water activity/Growth rate.

There are many kinds of fungi in dwelling environments. One of the predominant species is Cladosporium, and it can be isolated from the air, wall surfaces and home materials (Aihara et al., 2000a, 2000b, and 2001, Grant et al., 1989; Hunter et al., 1988). Though we have conducted an ecological investigation of Cladosporium in dwelling environments, there is little detailed information on the biological characteristics of Cladosporium, especially $C$. sphaerospermum and C. cladosporioides (Kawai et al., 1990). Since Cladosporium showed predominance with regard to distribution and population in dwelling environments, biodeterioration caused by Cladosporium also occurs in such environments (Moriyama et al., 1992). Therefore, Cladosporium caused biodeterioration is a very important concern. In

*Corresponding author. Tel: +81-3-3700-9048, Fax: +81-33700-9048. this paper, temperature and water activity (Aw) as physical factors, were briefly investigated in terms of their effects on $C$. sphaerospermum and $C$. cladosporioides.

The fungi used were five species of $C$. sphaerospermum MAF-23, 38, 61, 63, and 492 and five of $C$. cladosporioides MAF-24, 39, 58, 563, and 636 , isolated from dwelling environments.

Potato dextrose agar (PDA, Nissui Co.Ltd.), M40Y, M70Y, M100Y, MY10G, MY20G, MY30G, MY40G, MY55G and MY80G (Uchiyama et al, 1994) were used as media. Each type of media was supplemented with $50 \mu \mathrm{g} / \mathrm{ml}$ chloramphenicol and poured into $90 \mathrm{~mm}$-diameter sterile Petri dishes. The components and water activity (Aw) of these types of media are shown in Table 1. The Aw of each medium was measured with Hygroskop (Rotronic Co. Ltd.).

Ten- to 14-day-old colonies on PDA were used for all experiments. Spores of Cladosporium were 
TABLE 1. The components of medium used and Aw.

\begin{tabular}{|c|c|c|c|c|c|c|c|c|c|c|}
\hline \multirow[b]{2}{*}{ Component } & \multicolumn{10}{|c|}{ Medium } \\
\hline & $\begin{array}{l}\text { PDA } \\
(0.97)^{a}\end{array}$ & $\begin{array}{l}\text { M40Y } \\
(0.95)\end{array}$ & $\begin{array}{l}\text { M70Y } \\
(0.93)\end{array}$ & $\begin{array}{l}\text { M100Y } \\
(0.91)\end{array}$ & $\begin{array}{c}\text { MY10G } \\
(0.90)\end{array}$ & $\begin{array}{c}\text { MY20G } \\
(0.87)\end{array}$ & $\begin{array}{c}\text { MY30G } \\
(0.85)\end{array}$ & $\begin{array}{c}\text { MY40G } \\
(0.83)\end{array}$ & $\begin{array}{c}\text { MY55G } \\
(0.80)\end{array}$ & $\begin{array}{c}\text { MY80G } \\
(0.75)\end{array}$ \\
\hline Potato dextrose agar & $3.9^{b}$ & & & & & & & & & \\
\hline Malt extract & & 2 & 2 & 2 & 2 & 2 & 2 & 2 & 2 & 2 \\
\hline Yeast extract & & 0.5 & 0.5 & 0.5 & 0.5 & 0.5 & 0.5 & 0.5 & 0.5 & 0.5 \\
\hline Sucrose & & 40 & 70 & 100 & 100 & 100 & 100 & 100 & 100 & 100 \\
\hline Glycerol & & & & & 10 & 20 & 30 & 40 & 55 & 80 \\
\hline Agar & & 2 & 2 & 2 & 2.8 & 2.8 & 2.8 & 2.8 & 2.8 & 2.8 \\
\hline Distilled water & $100^{c}$ & 100 & 100 & 100 & 100 & 100 & 100 & 100 & 100 & 100 \\
\hline
\end{tabular}

${ }^{a} \mathrm{Aw}$.

${ }^{b} \mathrm{~g}$.

${ }^{\mathrm{c}} \mathrm{ml}$.

inoculated on the center of the agar plates. The incubation temperatures were $5,10,15,23,25,28,30$, 32,34 and $36^{\circ} \mathrm{C}$. Agar plates were then sealed with adhesive cellulose tape. After 28 days of incubation, the colony diameter was measured with a vernier caliper. Morphological changes of the growing Cladosporium hyphae under low Aw condition were also investigated in detail.

The minimum Aw needed for the growth of $C$. sphaerospermum and C. cladosporioides was investi- gated in the germination and spore production at 5-36 ${ }^{\circ} \mathrm{C}$ after incubation (Table 2 ). Regarding germination, the minimum Aw for $C$. sphaerospermum and $C$. cladosporioides ranged from 0.80-0.91 and 0.85-0.91, respectively. Regarding spore production, the minimum Aw for $C$. sphaerospermum was $0.80-0.91$ and that for $C$. cladosporioides was 0.87-0.95. From these results, $C$. sphaerospermum was shown with a slightly higher activity at low Aw.

To describe the growth activities of C. sphaero-

TABLE 2. Minimum Aw required for the germination and spore production at each temperature.

\begin{tabular}{|c|c|c|c|c|c|c|c|c|c|c|c|c|}
\hline \multirow{2}{*}{ Item } & \multirow{2}{*}{ Strain } & \multicolumn{11}{|c|}{ Temperature $\left({ }^{\circ} \mathrm{C}\right)$} \\
\hline & & 5 & 10 & 15 & 20 & 23 & 25 & 28 & 30 & 32 & 34 & 36 \\
\hline \multirow[t]{2}{*}{ Germination } & C. sphaerospermum & $0.90^{a}$ & 0.85 & 0.83 & 0.83 & 0.80 & 0.80 & 0.83 & 0.83 & 0.85 & 0.83 & 0.91 \\
\hline & C. cladosporioides & 0.90 & 0.85 & 0.85 & 0.87 & 0.85 & 0.85 & 0.90 & 0.87 & 0.91 & 0.90 & - \\
\hline \multirow[t]{2}{*}{ Spore production } & C. sphaerospermum & 0.93 & 0.91 & 0.85 & 0.85 & 0.80 & 0.80 & 0.83 & 0.83 & 0.85 & 0.85 & - \\
\hline & C. cladosporioides & 0.90 & 0.90 & 0.87 & 0.90 & 0.90 & 0.90 & 0.91 & 0.91 & 0.93 & 0.95 & - \\
\hline
\end{tabular}

${ }^{a}$ Mean value of $\mathrm{Aw}$ of 5 strains.

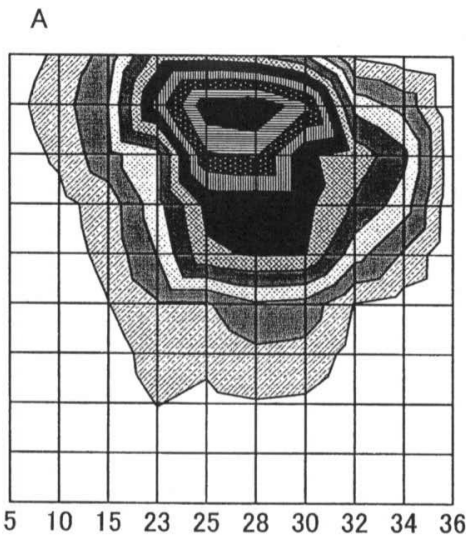

B

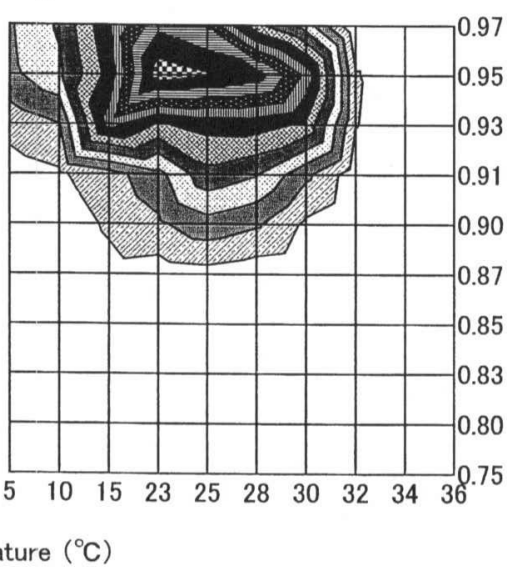

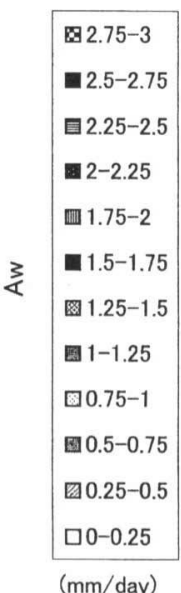

$(\mathrm{mm} /$ day)

FIG. 1 . Isopleth of temperature and water activity affecting the growth rate of $C$. sphaerospermum (A) and $C$. cladosporioides (B). 
spermum and C. cladosporioides as affected by temperature and $A w$, the growth rate (GR) was defined as follows: semidiameter ( $\mathrm{mm}$ )/incubation period (day) (Smith et al., 1982). The isopleth on temperature and $\mathrm{Aw}$ in $C$. sphaerospermum and $C$. cladosporioides is shown in Fig.1. The GR of $C$. sphaerospermum and $C$. cladosporioides was less than 0.25 at $A w 0.83$ and 0.88 , respectively, at all temperatures. At $A w 0.95$ and $28^{\circ} \mathrm{C}$, the highest value of $\mathrm{GR}$ at 2.72 was shown. The GR of $C$. cladosporioides was less than 0.2 at Aw0.87, but showed a high value when Aw was 0.93-0.97.

Though there was no difference at Aw0.93-0.97 and $23-30^{\circ} \mathrm{C}$ in the growth of $C$. sphaerospermum and $C$.

A

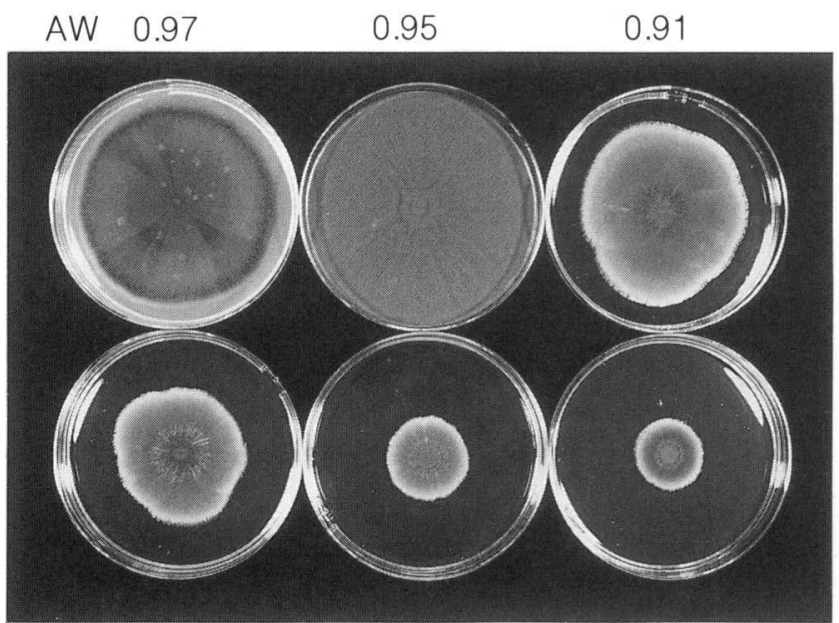

AW 0.90

0.87

0.85

cladosporioides, the former could grow at a lower Aw; GR was less than 0.25 at Aw0.83. The GR of the latter was less than 0.75 at $15^{\circ} \mathrm{C}$. At a low temperature, $C$. cladosporioides had a high GR, which was 1.50 at $15^{\circ} \mathrm{C}$.

From these results, it was thought that $C$. sphaerospermum could grow more easily than $C$. cladosporioides at high temperatures.

In the colony findings for various temperature and Aw conditions, C. sphaerospermum differed remarkably from $C$. cladosporioides. Also it was confirmed that $C$. sphaerospermum was more active than $C$. cladosporioides at a wide range of Aw. For example, Fig. 2 shows the colony growth patterns for $C$.

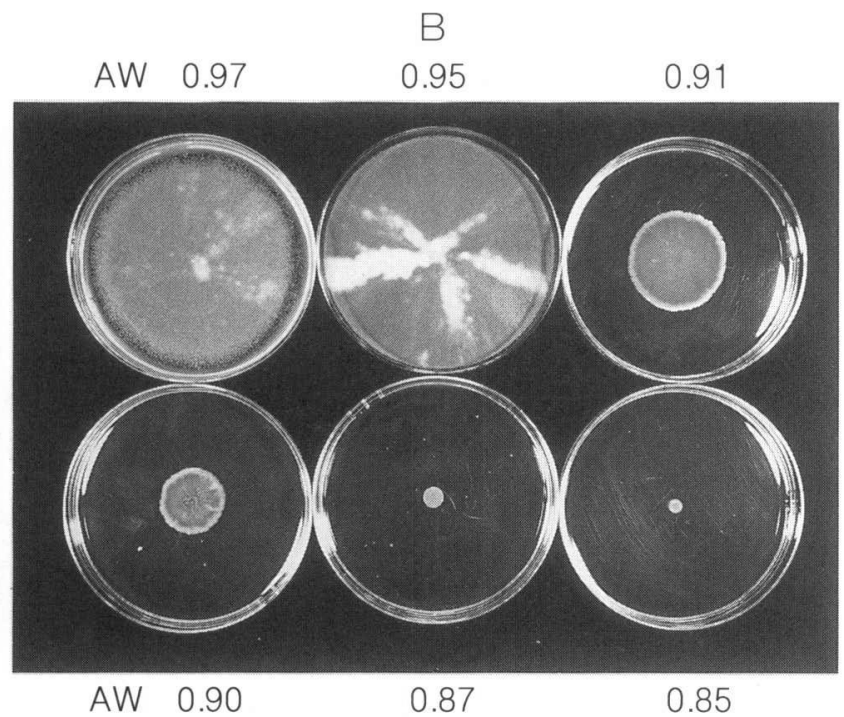

FIG. 2. Colony growth of C. sphaerospermum (A) and C. cladosporioides (B) at various Aw at $25^{\circ} \mathrm{C}$.

A

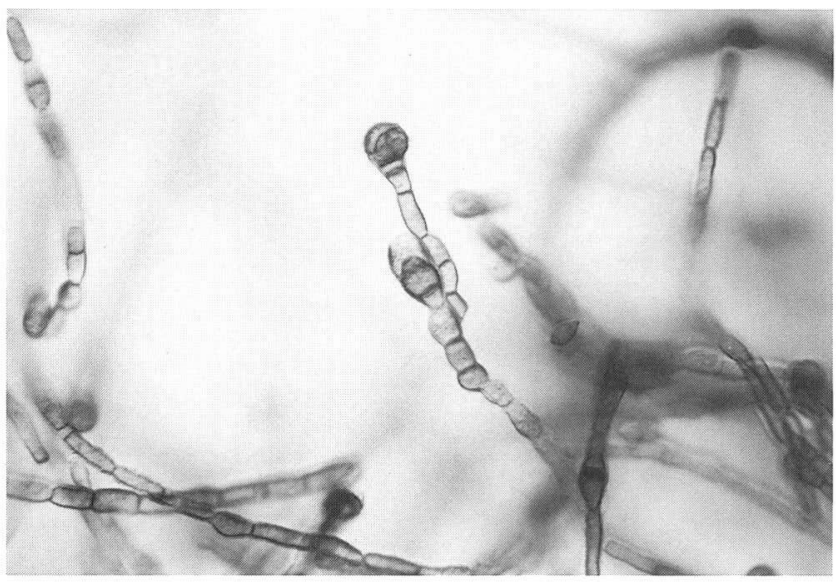

$B$

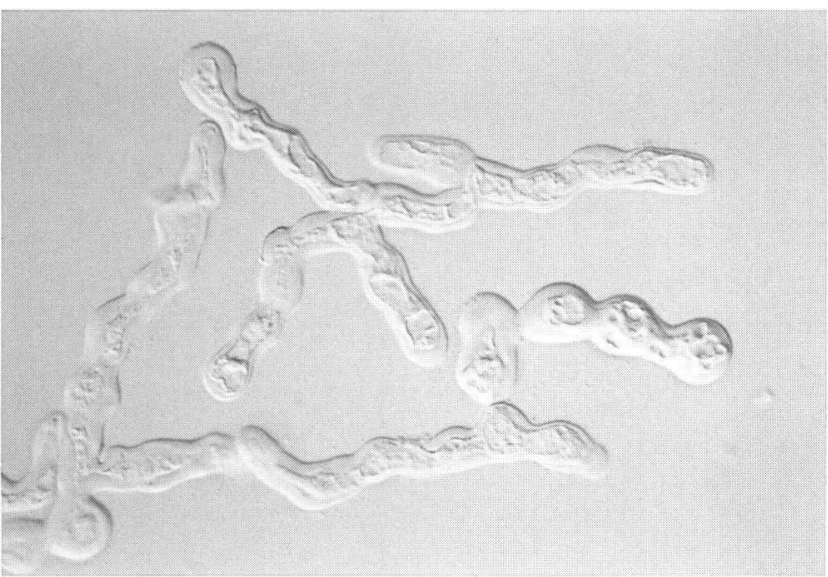

FIG. 3. Morphological changes of C. sphaerospermum (A) and C. cladosporioides (B) at $25^{\circ} \mathrm{C}$ and Aw of 0.85 after 28 days. Scale bar indicates $10 \mu \mathrm{m}$. 
sphaerospermum and C. cladosporioides at $25^{\circ} \mathrm{C}$.

Regarding morphological changes in $C$. sphaerospermum and C. cladosporioides under low Aw conditions irregular forms were seen. Under low Aw conditions, $C$. sphaerospermum and $C$. cladosporioides showed irregular hyphae with irregular, dark brown with thick and cigar shaped cells, and irregularly swollen cells at Aw0.85 for 28 days at 25 ${ }^{\circ} \mathrm{C}$ (Fig. 3). In general, Cladosporium hyphae grows with a constant width and septa in agar media. However, on natural materials, it grows with irregular morphology. Therefore, these hyphae in Fig. 3 are influenced by the abnormal environments such as low Aw. It shows that Cladosporium hyphae sometimes take abnormal forms like other fungi.

Some reports describe that Cladosporium is a fungus the minimum Aw to be 0.84-0.86 for growth (Grant et al., 1989; Magan et al., 1984; Pelhate, 1967). The optimal growth temperature was shown to be in the range of $20-30^{\circ} \mathrm{C}$ and Cladosporium is apparently sensitive to heat (Kawai et al.,1990). The predominant contaminant in house environments is Cladosporium, especially C. sphaerospermum and $C$. cladosporioides (Aihara et al., 2001). As factors related to fungal adherence to and penetration into housing materials, it was speculated that Aw and temperature are connected with fungal contamination. This paper focused on the main contaminationcausing species in Cladosporium such as $C$. sphaerospermum and C. cladosporioides. It was confirmed that $C$. sphaerospermum has a higher and also wider growth activity than $C$. cladosporioides with regard to the effects of the temperature and Aw.

\section{REFERENCES}

Aihara, M., Tanaka, T., and Takatori, K. (2001) Cladosporium as the main fungal contaminant of locations in dwelling environments. Biocontrol Sci., 6, 49-52.

Aihara, M., Tanaka, T., and Takatori, K. (2000a) Monthly changes of fungi detected from the indoor environments of a house structure (in Japanese). Bokin Bobai, 28, 3-8.

Aihara, M., Tanaka, T., and Takatori, K. (2000b) Fungal CFU and distribution on the upper, middle and lower vertical points of house walls (in Japanese). Bokin Bobai, 28, 421-426.

Grant, C., Hunter, C. A., Flannigan, B., and Bravery, A. F. (1989) The moisture requirements of moulds isolated from domestic dwellings. Int. Biodeterior., 25, 259-284.

Hunter C. A., Grant, C., Flannigan, B., and Bravery, A. F. (1988) Mould in buildings: the air spora of domestic dwellings. Int. Biodeterior., 24, 81-101.

Kawai, S., Takatori, K., and Ohtaki, T. (1990) Heat resistance of Cladosporium isolated from laboratory animal facilities (in Japanese). Exp. Anim., 39 (3), 319-323.

Magan, N., and Lacey, J. (1984) Effect of temperature and $\mathrm{pH}$ on water relations of field and storage fungi. Trans. Br. mycol. Soc., 82 (1), 71-81.

Moriyama, Y., Nawata, N., Tsuda, T., and Nitta, M. (1992) Occurrence of moulds in Japanese bathrooms. Int. Biodeterior. Biodegrad., 30, 47-55.

Pelhate, J. (1967) Determination of water requirements in grain storage fungi. Mycophathol. Mycol. Appl., 36, 117127.

Smith, S. L. and Hill, T. (1982) Influence of temperature and water activity on germination and growth of Aspergillus restrictus and A. versicolor. Trans. Br. mycol. Soc. 79, 558-560.

Uchiyama, Y., Noguchi, T., Tsuchibe, M., Mieno, Y., Kawashima, T., and Takatori, K. (1994) Studies on influence of temperature and relative humidity in fungal growth (in Japanese). Bokin Bobai, 22, 397-401. 